\title{
The application of geographic information system (GIS) in forensics geoscience
} School of Natural and Built Environment, Queen's University Belfast, BT7 1NN, Northern Ireland, UK; Communications Officer, International
Union of Geological Sciences, Initiative on Forensic Geology (IUGS-IFG); *Corresponding author, E-mail: j.mckinley@qub.ac.uk

(Received: November 17, 2016; Revised accepted: March 9, 2017)

http://dx.doi.org/10.18814/epiiugs/2017/v40i2/017019

Advances in technological developments in Geographic Information Systems (GIS) has enabled the application of GIS in landscape mapping, environmental management, natural hazard risk and disaster management. As geographical information becomes more widely available through satellite and aerial imagery, the cost of software decreases and GIS expertise expands, it is most likely that the use of GIS will increase. The methodology has practical applications for police, crime scene investigators and forensic geoscientists. The aim is to develop GIS use in forensic search beyond mapping to offer a set of decision support tools that utilise the spatial analytical capabilities of GIS. This enables better management and understanding of the complicated and interrelated nature of a ground search.

\section{Introduction}

Since the technological advances of Geographic Information Systems (GIS) during the 1980s and 1990s, the application of GIS has been used extensively in landscape mapping, environmental management, natural hazard risk and disaster management (Zerger and Smith, 2003). As geographical information becomes more widely available through satellite and aerial imagery, the cost of software decreases and GIS expertise expands, it is most likely that the use of GIS in search and rescue, criminalistics, and other investigations may increase. Despite the use of GIS being well established in crime density mapping, identifying hot spots and patterns over time since the 1990s, GIS capability has not been routinely used in the collection of trace evidence and in search strategies for missing persons, homicide graves or other buried objects (Donnelly, 2003; Harrison and Donnelly, 2007, 2008, 2009; Ruffell and McKinley, 2008; McKinley et al., 2009; Donnelly and Harrison, 2010; McKinley 2013). It has however been used in some search investigations, e.g., In Scotland in the search for Moira Anderson, Police Scotland, 2014 to present (personal communications, Lorna Dawson). Historic maps from 1957, mine infrastructure, soil, geology, and land cover have all been brought together along with witness accounts using an ArcGIS system to create a working GIS model.

Using GIS can provide a planning base for decision making in forensic ground search strategies. In collaboration with UK, European Forensic Science Regulators and law enforcement agencies worldwide, IUGS-IFG has been involved in a number of international training workshops. A GIS-based methodological approach has been demonstrated to collect, integrate and analyse different types of geo-referenced data useful in forensic ground search investigation to increase the potential for a higher degree of success in search operations. The methodology has a practical application for police, crime scene investigators and forensic geoscientists. The aim is to develop GIS use in forensic ground search beyond conventional mapping to offer a set of decision support tools that utilises the spatial analytical capabilities of GIS and enables better management and understanding of the complicated and interrelated nature of some forensic ground searches. The broad objectives of the GIS-based landscape modelling approach for ground search have been to:

- Develop a GIS methodology to model landscape search scenarios.

- Develop a methodology to identify 'markers' in the landscape for a feature focused search and identify search 'catchments'.

- Develop a methodology that can be assessed in the context of improved decision making for ground searches.

- Longer term, to test the effectiveness of a real-time GIS-based ground search decision-making tool.

Examples are provided based on material produced for an IUGSFG forensic geology training workshop which was held with the Australian Federal Police in Brisbane, Australia, in 2012 and one developed for an ongoing missing person in the west of Ireland.

\section{A GIS Methodology to Model Landscape Search Scenarios, Example 1 Brisbane, Australia}

GIS has become an essential part of the traditional desktop study as more geographic, topographic, soil and geological information becomes available in digital format. Remotely acquired aerial imagery generated by aircraft or unmanned aerial vehicles (UAVs), satellite imagery, thermal and multispectral imagery and land use information have become more readily available over the last 10 years. An increasing amount of historical edition maps and topographical maps has already been geo-rectified by government mapping agencies and made available in digital form. Additional information such as photographs, witness accounts and sketches, may also be available. As it is most likely 
that these will be in paper form, the information needs to be scanned and geo-rectified and geo-referenced to other digital data layers.

An example from the IUGS-IFG training workshop Brisbane, Australia, 2012 compares a geo-rectified, scanned pdf of a 1987 soils map of the Brisbane region (Fig. 1a) with the soil data represented in spatial data format (Fig. 1b). This GIS study confirms that the field site lies on a combination of gravelly red and yellow podzolic soils and lithosols. The 1987 soils map is from the Atlas of Australian Soils and was created by CSIRO in the 1960s to provide a consistent national description of Australia's soils (Northcote et al., 1960-68). The original compilation of the maps was at scales from 1:250,000 to 1:500,000 but the maps are published at a scale of 1:2,000,000. Digitisation of the Atlas was undertaken by the Bureau of Rural Science in 1991, from scanned tracings of the published hardcopy maps. The current soil landscapes were mapped at a scale of 1:100 000 by CSIRO (CSIRO, 2016).

Data quality is important and it is vital that data are checked for completeness, consistency and positional accuracy. Metadata (i.e., information about the data) including understanding the impact of date, scale and resolution of different available information is essential to ensure the correct inferences are made from the use of data. For example soil polygon boundaries, such as those digitised by CSIRO, are probabilistic interpretations of changes in soil or land type, which in reality will represent graduated soil boundary changes (CSIRO, 2016). Notwithstanding a degree of uncertainty, the integration of informa-

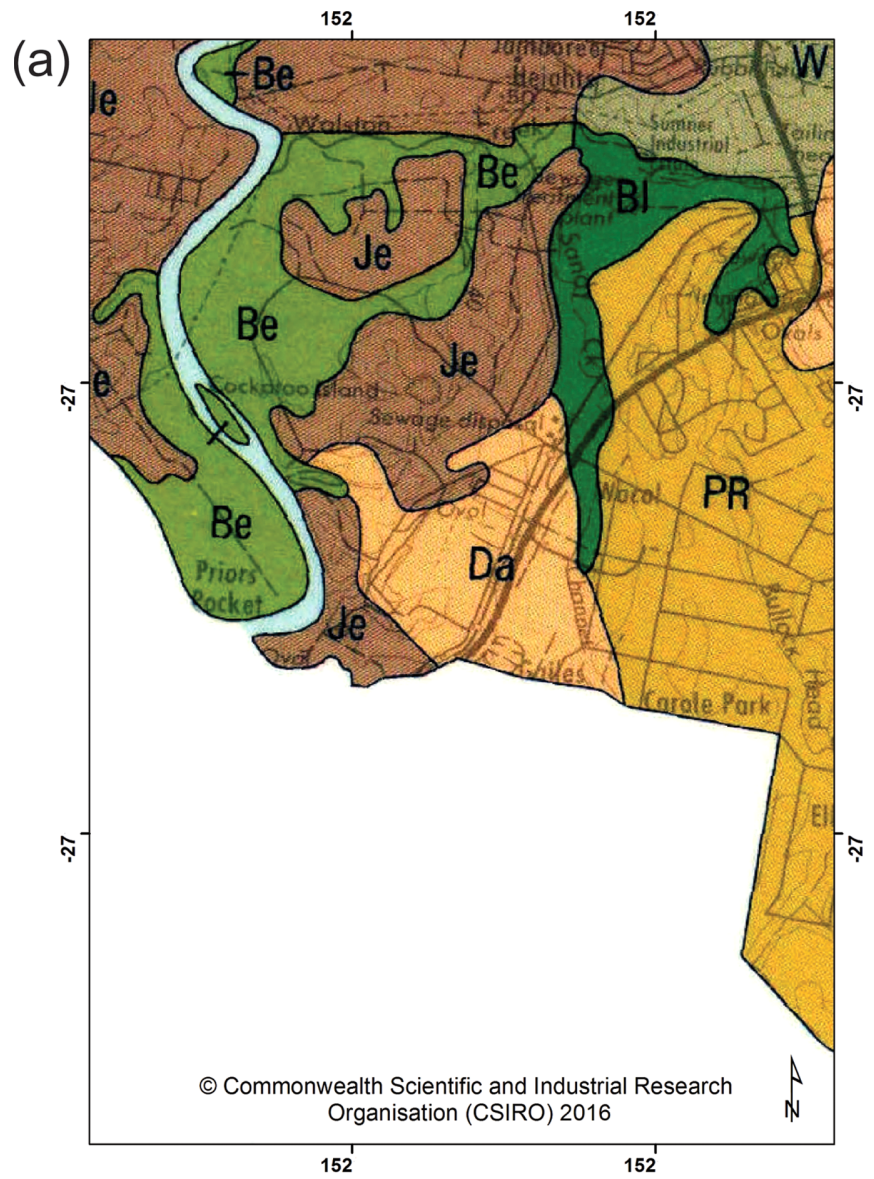

tion as additional geo-referenced spatial layers increases the opportunity to query information to inform police, search and forensic investigators.

Terrain analysis and geomorphological mapping may provide information and increased insight to identify both areas of exclusion and identify potential search areas. Elevation data are becoming increasingly available acquired either from ground surveys, airborne photogrammetry, radar and or LiDAR (Light Detection and Ranging) surveys or from satellite imagery. The resolution of elevation data may vary from $\mathrm{cm}$ to tens of metres depending on the techniques used. This will have an impact on any generated elevation surface and consequently on interpretation based on this. In the case where elevation data are not accessible, elevation can be generated from digitising contours from available base maps. For the Brisbane area contours were digitised from a geo-rectified scanned base map (Fig. 2a). This provided an elevation data set that can be interpolated to create a terrain model (Fig. 2b) in 2D form or used to view the landscape from different $3 \mathrm{D}$ viewing perspectives (Figs. $2 \mathrm{c}$ and d).

A Global Navigation Satellite System (GNSS), such as a hand held units or differential geomatics can be added to the GIS model. Figure 3 shows the recorded track of an Australian Federal Police (AFP) officer during the IUGS-IFG training workshop. A range of different materials including ferrous and non-ferrous objects were buried as part of this training to simulate the burial of weapons, explosives and drugs. The diggability of the ground was determined by a forensic geologist (Donnelly and Harrison, 2009; Ruffell and McAllister, 2015)

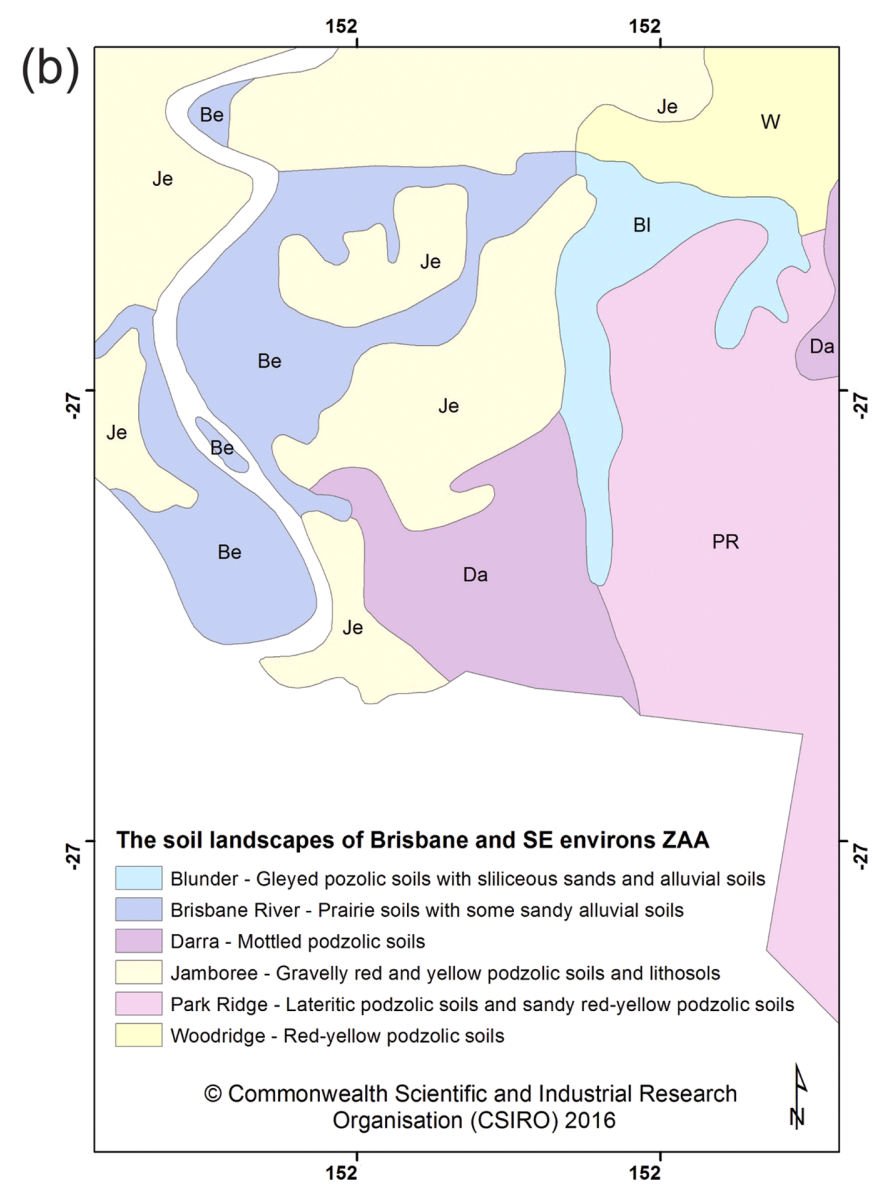

Figure 1. (a) Geo-rectified scanned pdf of a 1987 soils map and (b) soil data represented in spatial data format. Southeast Brisbane region, Queensland, Australia (IUGS-IFG training for AFP, 2012). 

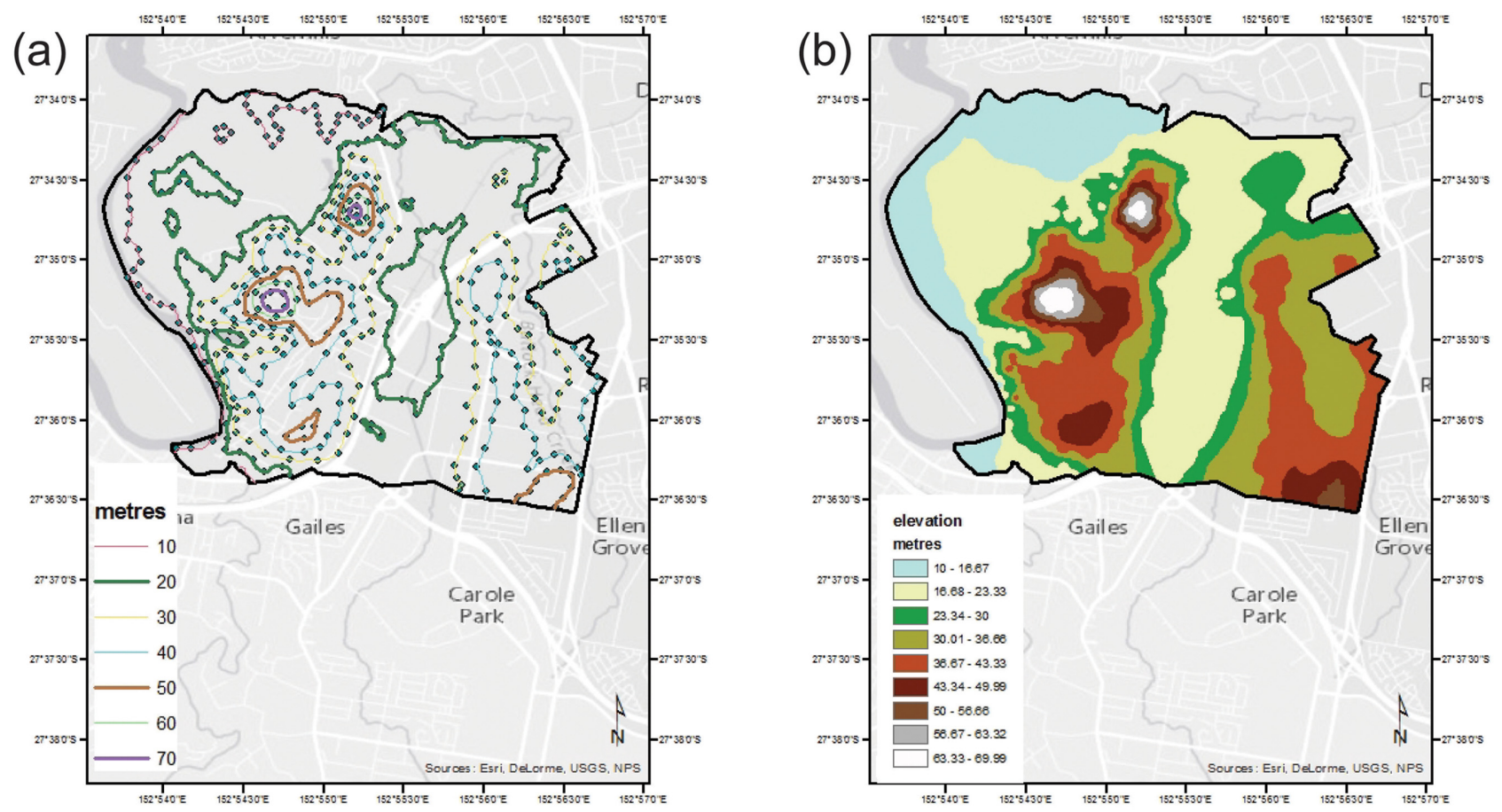

(c)
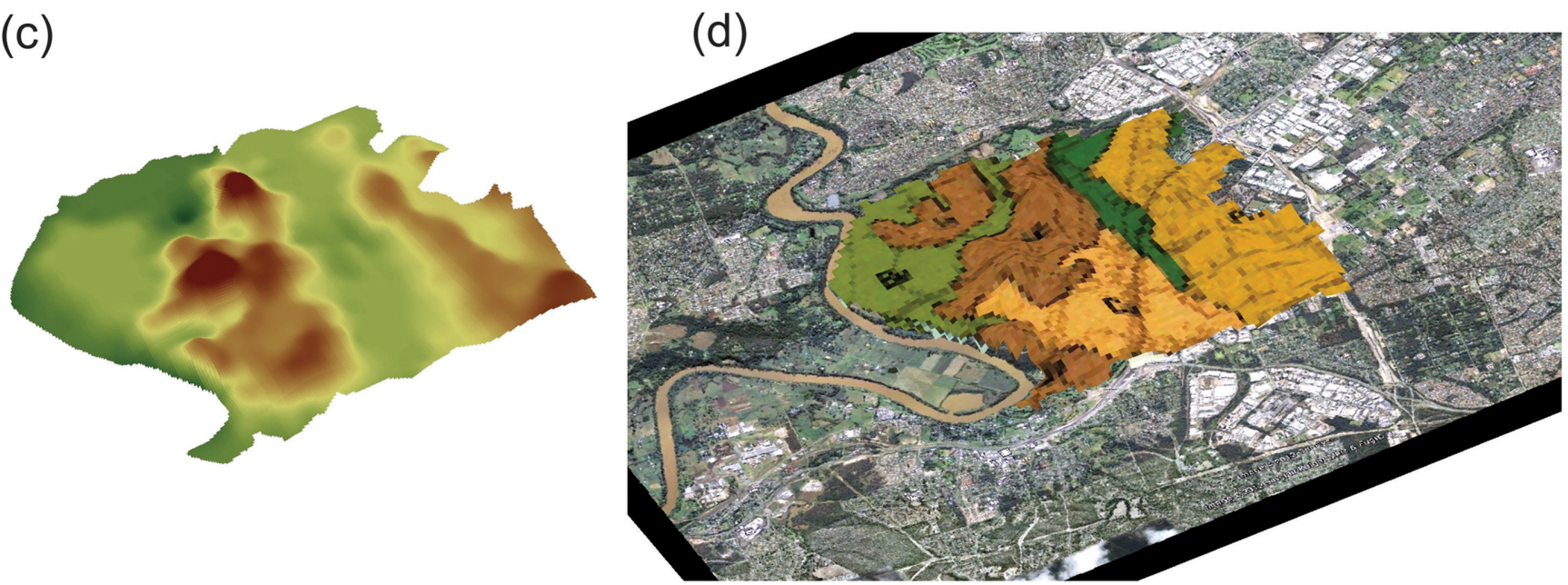

Figure 2. (a) Digitised contours from a geo-rectified scanned base map; (b) Interpolated terrain model; (c) Elevation model in 3D form; (d) overlain $3 D$ viewing perspective. Southeast Brisbane region, Queensland, Australia (IUGS-IFG training for AFP, 2012).

based on soil type, depth, the presence of groundwater, bulking properties of the soil and suspected digging implement used. The GIS analysis provided a distribution of the geographic variability in diggability properties across the search area, and therefore reducing areas of low burial probability.

The location of physical features of the landscape, such as a rock exposure or a solitary tree may also be recorded as these could have been used by an offender to navigate across the landscape. In Figure 3 , the AFP officer has recorded the burial site to be located between two trees. Once the location of ground disturbances and physical markers have been recorded and geo-located, these can be entered into the GIS and assessed against existing police information and previously identified anomalies, as observed from a reconnaissance walk over survey.

\section{GIS Methodology for Marker Identification}

A GIS study may assist in identifying the outer limits of the search area using physical features of the landscape, such as the presence of a river or a break in slope that would provide a natural cut-off for the search limits boundary. Buffers can be created to define different search zones that represent distances that are possible when crossing an area by foot to identify priority search locations for geographic and environmental profiling.

Natural or artificial distinctive or prominent reference points, are useful 'markers' in the landscape, such as Winthrop or object based markers (Donnelly, 2007) and can be geo-located using GNSS for further GIS analysis. Such markers could also be identified from a deskbased GIS study as primary, secondary or tertiary and verified during 


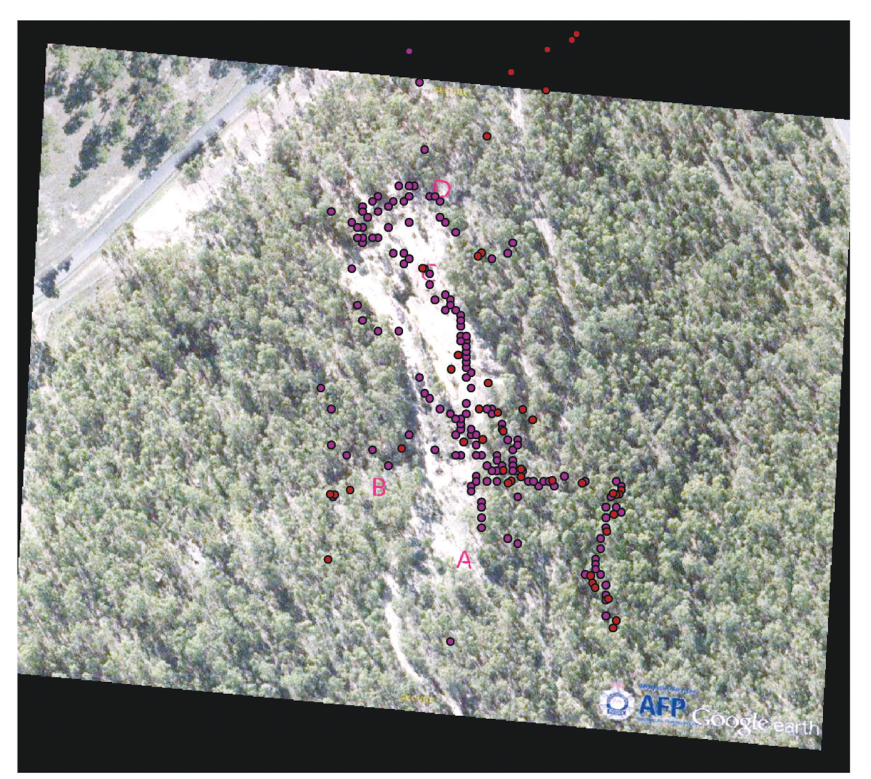

Figure 3. Ground search using GPS (IUGS-IFG training for AFP, 2012).

a ground reconnaissance walk over survey. Once a terrain surface is created (Fig. 2), this can be used for further processing to produce hill shade maps and generate slope and aspect information. Information on changes in slope can reveal hidden parts of the landscape or model the movement of surface and groundwater flows. Aspect allows potential drainage patterns to be considered. Drainage may be important to some ground searches, as body scent may potentially be transported by leachate plumes to emerge at the ground surface at natural springs or seeps (Donnelly, 2008). Integrating information about topography, slope, aspect, soils, geology and groundwater helps to define catchments, watersheds, drainage networks and therefore the likely movement of potential leachate plumes (Donnelly et al., 2016).

\section{GIS Methodology for Improved Decision-mak- ing, Example 2, Ireland}

A person in the west of Ireland was reported as missing. The search centered on a location on a quiet country road along a farm track where fields passed into scrubland (McKinley et al., 2009). A GIS analysis was undertaken that integrated information from a previous field-based survey completed in 2003 (Ruffell and McKinley, 2008) with all newly available digital information, including historical data, geology, soils, aerial imagery and Near-Infrared Spectrometry (NIR) data (Fig. 4).

Historical data provided information on the original ground conditions (marshy, wetlands) and the direction of overland and ground water flow (Fig. 4a). Using a technique called the Normalized Difference Vegetation Index (NDVI), near-Infrared (NIR) remotely sensed (a)

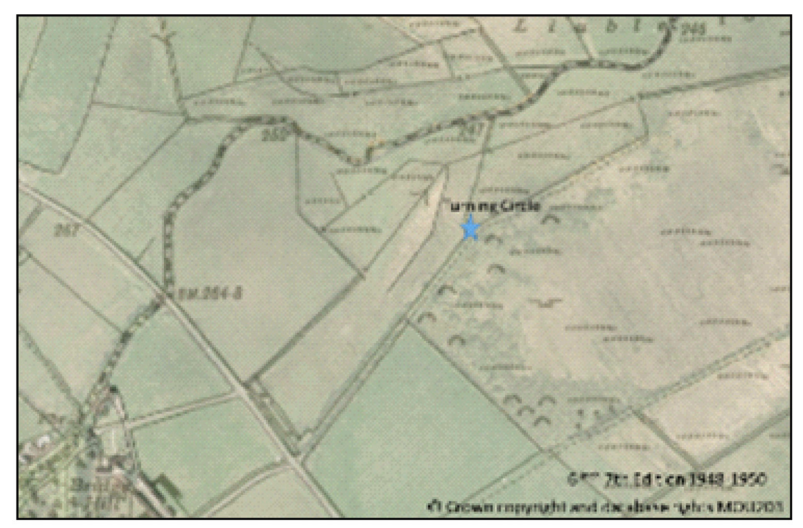

(c)

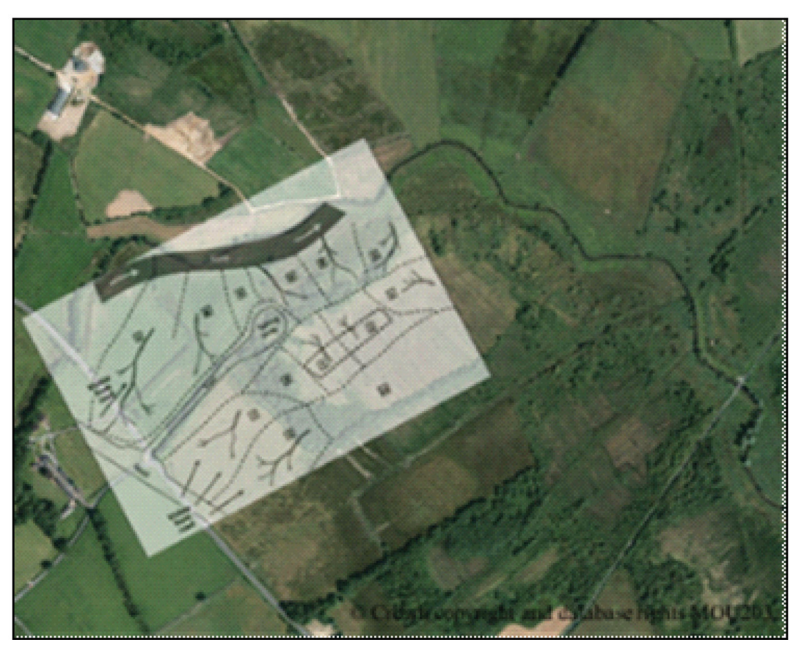

(b)

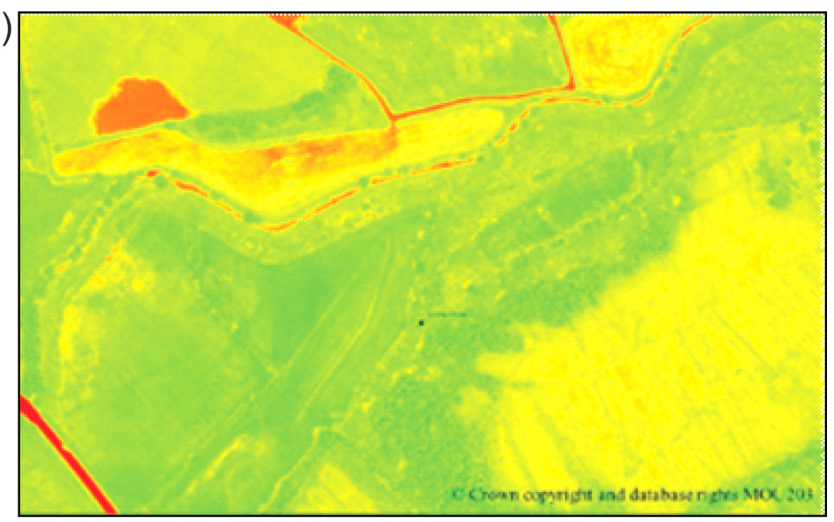

(d)

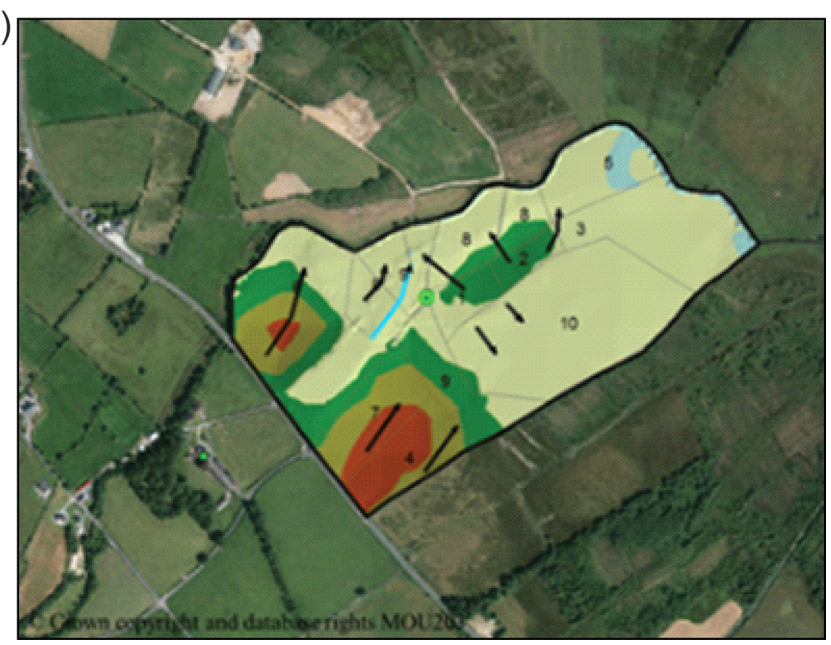

Figure 4. (a) Original ground condition using historic maps; (b) Exposed soil and vegetation types shown by NIR imagery; (c) Defined search areas; (d) Revised search areas. (C) Crown copyright and database rights MOU203). 
imagery has been used to identify vegetated and non-vegetated surface topography for the area (Fig. 4b). Near-Infrared wavelengths $(750-1400 \mathrm{~nm})$ are found just outside the visible range of the human eye $(>700 \mathrm{~nm})$ and are of particular value when analysing surface vegetation cover. Plants tend to reflect NIR wavelengths, and in general the healthier the plant or denser the vegetation the more NIR they reflect and the more Red wavelength they absorb. Based on this principal the NDVI can be used to identify vegetation and non-vegetation in a captured multispectral image. The index normalises the visible Red and NIR bands to a ratio of between -1 and +1 where no vegetation is calculated as -1 and denser or healthier vegetation is calculated towards +1 . As NIR is also reflected by structures and water bodies, the index can also be used to identify non-vegetative surfaces such as rivers, roads, exposed soils and human disturbance. This can be especially useful for landscape search scenarios. In the missing person case (Fig. 4b) the river course and exposed soil is observed as red (-1), marshy ground and wetlands are shown as yellow (between +1 and -1 ) and grass covered areas are green $(+1)$. Overlaying and geo-rectifying the field sketch from the 2003 search allows the landscape to be divided into search areas and compared with historical and contemporaneous information (Fig 4c). This provides an updated landscape search model (Fig. 4d) which integrates information on topography, hydrology and search domains. This provides additional information for the forensic geologist to create diggability and RAG (Red-AmberGreen) search prioritization maps (Donnelly and Harrison, 2013; Ruffell and McAllister, 2015).

Cost distance analysis within a GIS calculates the cost of effort associated with moving from one point on a terrain to another point. This can be useful in searches to consider behavioral aspects of a burial and the 'least effort principle' whereby the effort of digging to achieve a satisfactory grave is weighed against the effort and time expended to achieve this, considering the available resources of tools at hand (Donnelly and Harrison, 2009).

Line-of-sight or viewshed maps determine what areas of the terrain may be seen from one location but not from another. Hidden areas in a landscape are of interest rather than the viewable locations from the perspective of the perpetrator. A number of different viewsheds can be created and overlapped to create composite viewshed maps. Within a GIS analysis the relationship between known police information, collected evidence and created viewshed and cost analysis maps can be fully assessed. For the missing person case a number of viewsheds were created to show the areas of the landscape, which would have been hidden from view from a car turning point, a key location provided from police information (Fig. 5a) and areas within the landscape that would not have been easily observed by houses in proximity to the area (Fig. 5b).

The GIS framework was used to create an integrated database and data management system to show low, moderate and high priority search areas (Fig. 6). These were then assigned weightings on the basis of seven elements: ease of terrain, slope steepness, geology, soil properties, visibility index, hydrology and dog indication. The resultant map, for this ongoing search operation, provides a domain score indicating high priority search areas (scored 4 in Fig. 6).

\section{Real-time GIS-based Decision-making Tool}

The recording of evidence and information by a law enforcement officer or forensic geologists can result in information overload.This can result in, vast amounts of potentially useful information not being fully utilised due to a lack of resources, time or pressure to quickly produce results. Adjunct to information and evidence collection at a crime scene is the role of accessing existing, available and relevant information including data on soils, geology, vegetation, land cover and topography. The concept of a real-time GIS-based forensic decision-making tool is to offer an interface between information collection and spatial analytical to provide regular updates and advice for an ongoing investigation or search. The objective is to provide an integrated platform with access to spatial technologies, spatial data layers, databases to provide real time maps and advice for more effective and efficient crime scene management and as a result increased success rate for search activities. (a)

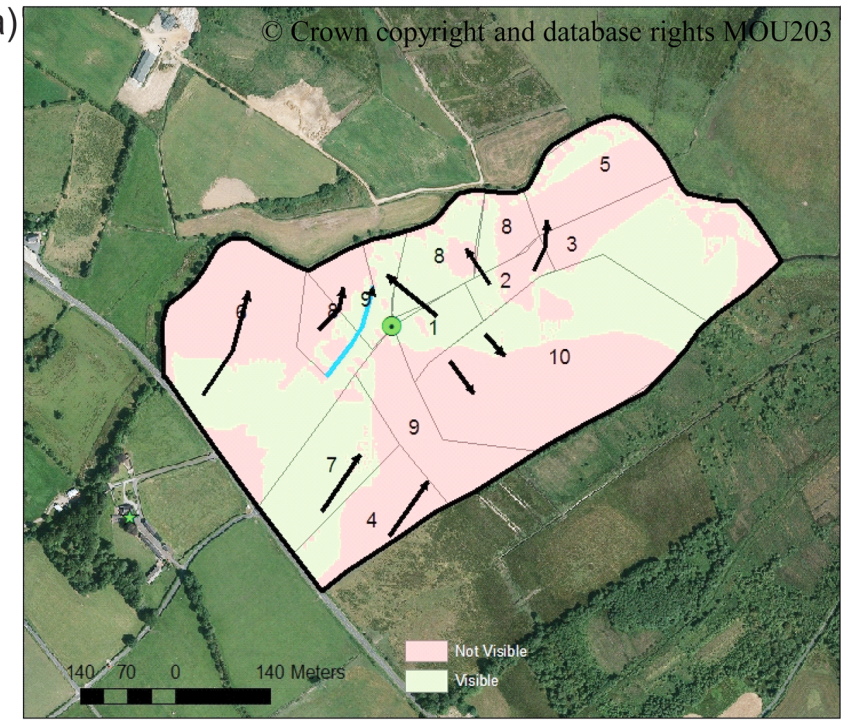

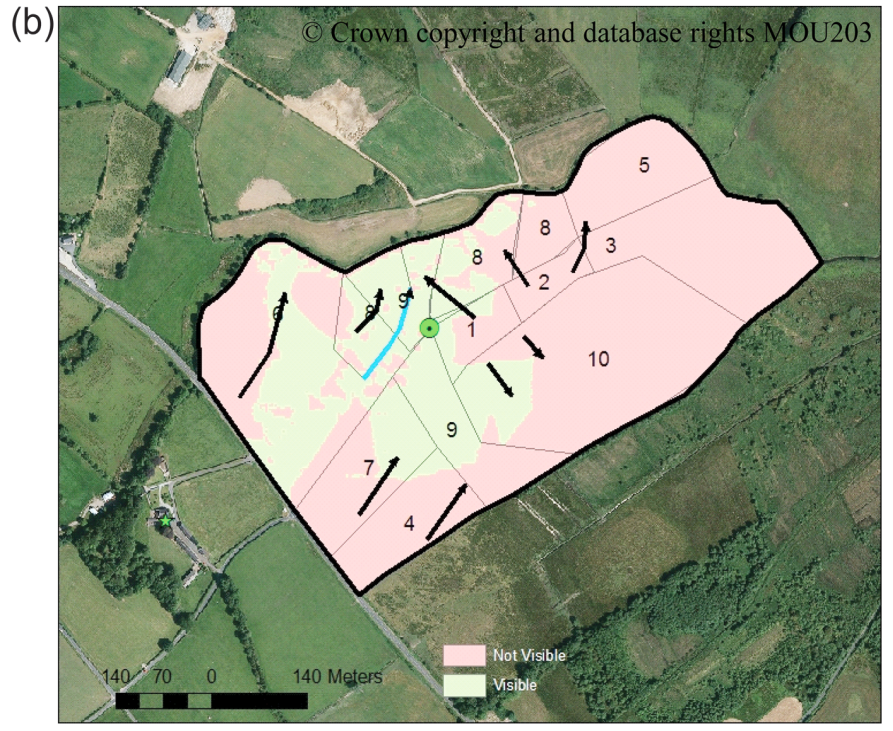

Figure 5. Viewshed analysis from (a) the turning circle and (b) houses (as discussed in the text). 


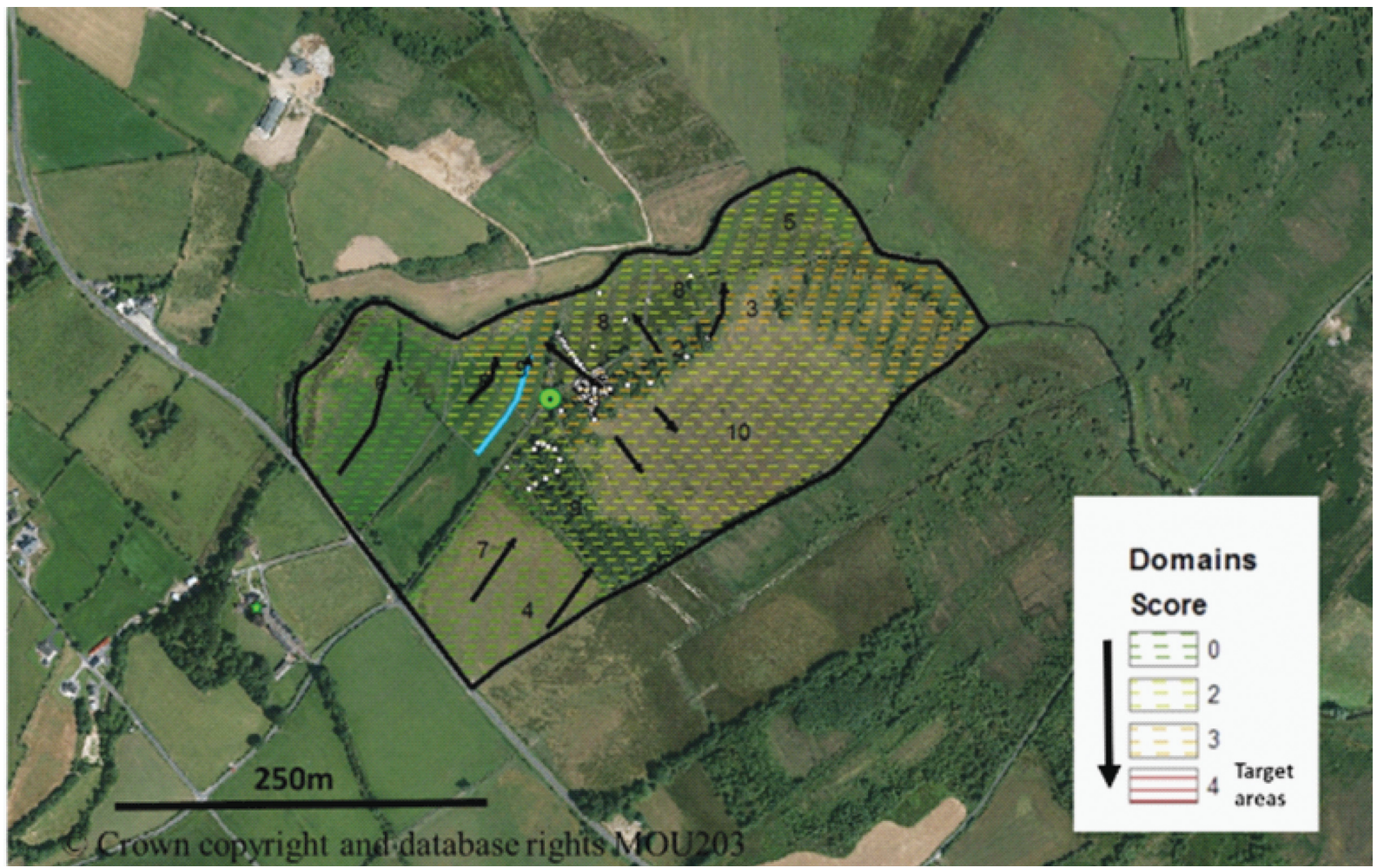

Figure 6. Domain ranking as a decision making tool.

\section{References}

Donnelly, L.J., 2003, The applications of forensic geology to help the police solve crimes. European Geologist: Journal of the European Federation of Geologists, v. 16, pp. 8-12.

Donnelly, L.J., 2008, The development and significance of a conceptual geological model, in different geomorphological settings, to search, to search for a murder victim's grave. in Donnelly, L.J. (ed.), Geoscientific equipment and techniques at crime scenes: $2^{\text {nd }}$ FGG Meeting of the Geological Society of London, Forensic Geoscience Group, Programme \& Abstracts, Burlington House, London, December 17, pp. 36-38.

Donnelly, L.J., 2013, Use of geology in forensic science: search to locate burials. in Elias, S.A. (ed.), The encyclopaedia of Quaternary science: Elsevier, Amsterdam, v. 4, pp. 521-534.

Donnelly, L.J., and Harrison, M., 2013, Geomorphological and geoforensic interpretation of maps, aerial imagery, conditions of diggability and the colour coded RAG prioritisation system in searches for criminal burials. in Pirrie, D., Ruffell, A.R., and Dawson, L. (eds.), Environmental and criminal geoforensics: Geological Society of London, Special Publication, v. 384, pp. 173-194.

Donnelly, L.J., Cassella, J., Pirrie, D., Dawson, L., Harrault, L., Blom, G., Davidson, A., Arnold, P., Harrison, M., and Ruffell, A., 2016, Analysis of leachate, VOCs, fatty acids and mineralogy following the discovery of a homicide grave: potential implications for police led open area ground searches for burials: $35^{\text {th }}$ International Geological Congress, Cape Town, August 29, T6.1 - Forensic Soil Science and Geology.

Harrison, M., and Donnelly, L.J., 2009, Locating concealed homicide victims: developing the role of geoforensics. in Ritz, K., Dawson L., and Miller, D. (eds.), Criminal and environmental soil forensics: Springer Science + Business Media B.V., pp. 197-219.

McKinley, J., 2013, How useful are databases in environmental and criminal forensics? in Pirrie, D., Ruffell, A.R., and Dawson, L. (eds.),
Environmental and criminal geoforensics: Geological Society of London, Special Publication, v. 384, pp. 109-119.

McKinley, J., Ruffell, A., Harrison, M., Meier-Augenstein, W., Kemp, H., Graham, C., and Barry, L., 2009, Spatial thinking in search methodology: a case study of the 'No Body Murder Enquiry', west of Ireland. in Ritz, K., Dawson, L., and Miller, D. (eds), Criminal and environmental soil forensics. Springer Science + Business Media B.V., pp. 285-302.

Northcote et al., 1960-68, Digital atlas of Austrialia soils: https://data. gov.au/

Ruffell, A. and McKinley, J., 2008, Geoforensics: Wiley-Blackwell, Hoboken, $332 \mathrm{p}$.

Ruffell, A. and McAllister S., 2015, A RAG system for the management forensic and archaeological searches of burial grounds: International Journal of Archaeology, v. 3, pp. 1-8.

Zerger, A., and Smith, D.I., 2003, Impediments to using GIS for real-time disaster decision support: Computers, Environment and Urban Systems, v. 27, pp. 123-141.

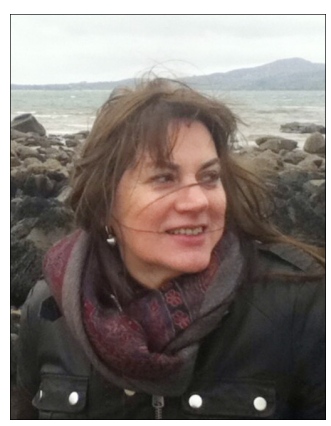

Jennifer McKinley is a Chartered Geologist and Council Member of the Geological Society of London. She currently holds a number of roles including President of the International Association of Mathematical Geoscientists (IAMG) and Communications Officer for the IUGS-IFG. With a primary degree and doctorate in geology, her work has focused on the application of spatial analysis techniques, including geostatistics and Geographical Information Science (GIS), to soil geochemistry, environmental and criminal forensics, health, airborne geophysics and weathering studies. 